\title{
Atraumatic Restorative Treatment with Resin-Modified Glass Ionomer Material: Short-Term Results of a Pilot Study
}

\author{
Ç. Türksel Dülgergil ${ }^{a}$ Mübin Soyman ${ }^{b}$ Arzu Civelek ${ }^{b}$ \\ Departments of Operative Dentistry, ${ }^{a}$ Kirikkale University, Kirikkale, and ${ }^{b}$ Yeditepe University, Istanbul, Turkey
}

\begin{abstract}
Key Words
Atraumatic restorative treatment - Glass ionomer cement $\cdot$ Resin-modified glass ionomer
\end{abstract}

\begin{abstract}
Objectives: The aim of this study was to assess the feasibility of the resin-modified glass ionomer (RMGI) material in atraumatic restorative treatment (ART) approach and compare RMGI with the high-strength traditional glass ionomer cement $(\mathrm{GIC})$ in permanent teeth with one or more surface-carious cavities. Materials and Methods: This study was conducted in a village school in rural southeastern Anatolia, Turkey. The RMGI and GIC restorations with the ART technique were placed randomly employing a split mouth design. In addition, the ART approach was used when necessary for both primary and/ or permanent teeth with no pulpal involvement and no perceived pain before treatment. Ninety-one fillings were placed on contralateral molar pairs of 37 children. Baseline and 6-month evaluation of the fillings were made with the classic ART, modified Ryge and USPHS criteria. Results: Based on the ART criteria, $100 \%$ of RMGI and $92.4 \%$ of GIC restorations were classified as successful after 6 months, and the difference between the 2 groups was statistically significant $(p=0.009)$. While marginal discoloration was the commonest failure in the
\end{abstract}

RMGI group according to both the modified Ryge and USPHS criteria, unsatisfactory surface texture and low anatomic form were the commonly seen failures in the ART technique. Conclusion: Generally, for each rating system, RMGI exhibited better clinical performance than GIC in all categories, except for marginal discoloration. Results based on the 6-month evaluation show that RMGI can be an alternative material to the GIC.

Copyright (C) 2005 S. Karger AG, Basel

\section{Introduction}

In less-developed communities with little chances of dental care, atraumatic restorative treatment (ART) became a useful alternative for tooth extraction [1]. In an earlier ART study carried out in Thailand, the survival rates of single-surface ART restorations placed in permanent teeth were 93,83 and $71 \%$ after 1,2 and 3 years, respectively [2]. The outcomes were similar to those of amalgam restorations placed in a related population in the same study, but the difference was statistically significant.

Since the success of the ART technique depends to some extent on the restorative material, it is useful to carry out clinical studies using various materials such as polyacid-modified composite resins and resin-modified

\section{KARGER}

Fax +41613061234

E-Mail karger@karger.ch

www.karger.com
(C) 2005 S. Karger AG, Basel

1011-7571/05/0144-0277\$22.00/0

Accessible online at:

www.karger.com/mpp
Çoruh Türksel Dülgergil

Department of Operative Dentistry

Dental Faculty, Kirikkale University

TR-71200 Kirikkale (Turkey)

Tel. +90 318224 4927, Fax +90 318224 3618, E-Mail turkseld@yahoo.com 
glass ionomers (RMGI). The aims of this study were to assess the feasibility of the RMGI material in the ART approach and to compare this material with the highstrength traditional glass ionomer cement (GIC) in permanent teeth with one or more surface-carious cavities.

\section{Subjects and Methods}

This study was conducted in rural districts of Diyarbakir City, southeastern Anatolia, Turkey. A primary school in a small village with a low socioeconomic condition was selected, and 37 children with at least two sites with caries that would permit vital therapy in the contralateral permanent teeth were included in the study. Informed consent was obtained from children's parents. The age range was 9-13 (mean $11.3 \pm 2.1$ ), and the mean DMFT was 3.02 \pm 2.3 .

A split mouth method was used, one tooth for test and the other for control within the same jaw. The materials studied were RMGI (Vitremer, ESPE $\backslash 3 \mathrm{M}$ ) and GIC (Ketac-Molar, ESPE $\backslash 3 \mathrm{M}$ ). When one of the two materials was performed on a carious tooth, the other tooth in the same jaw was filled with the other material. With this procedure, a minimum of two and a maximum of five restorations were placed in one dentition. The ART restorations with GIC served as the control group.

Children were treated in school environment while lying on a school desk. All treatment procedures were performed by one experienced dentist (C.T.D.) during a 2-month period. For the application of RMGI material, the steps followed were: (a) Isolation with cotton wool rolls of the operated quadrant. (b) Removal of the decay tissue and providing a pulpal protection, if necessary. After cleaning the tooth surface and widening the entrance of the lesion by hatchets, soft caries was first removed from the dentin-enamel junction, and then from the floor of the cavity, using spoon excavators. If the carious lesion extended deep into dentin, a thin layer of a calcium hydroxide liner was carefully placed on the bottom of the cavity to provide pulpal protection. (c) Conditioning of the entire dentinal surface, including dentinal tissue into the cavities with a solution provided by the manufacturer, using an adequate size cotton pellet. (d) Mixing of the Vitremer material into condensable cement consistency proportion using 2-3 powder measure for every drop of liquid and squeezing the material into the cavity using a special applicator. (e) Pressing with gloved finger and checking the bite; before the light curing, to avoid air bubbles, in order to secure the material in the cavity and remove excessive material, the initial press with the finger coated with petroleum jelly was performed, and a slight pressure was applied. Then, since the material would have been too hard to trim after curing, occlusion adjustment was performed immediately before curing. (f) Curing the material and rechecking the filling. For adequate polymerization, at least 40 - to 60 -second light curing with LED (Dentaline LED 1000, RF System, Turkey) was necessary.

If an RMGI filling was placed on the right side of a child's jaw, in the next child the same material was used on the opposite side. A total of 91 restorations were made. Of the 52 restorations in the RMGI and 39 restorations in the GIC group, 21 and 17 had two surfaces, respectively. The two dentists who conducted the baseline examination did not do the filling but carried out quality assess- ment at both baseline and 6 months later using the ART, USPHS and modified Ryge criteria. Evaluation consistency was assessed on a sample of 30 fillings (15 RMGI and 15 GIC) in 20 children. In case of disagreement, another evaluation based on consensus was made. According to the ART rating system, a restoration was assessed as successful if it was either recorded as score 0,1 or 7 [2]. In the examination of the fillings, while a ball-ended CPI probe $(0.5$ $\mathrm{mm}$ in diameter) was used for the ART criteria, a sharp explorer was preferred for the USPHS criteria. A new probe was used after every 20 examinations to ensure a reliable application of the tactile diagnostic criteria. For statistical analysis, McNemar's and $\chi^{2}$ tests were used with the significance set at $\mathrm{p}<0.05$.

\section{Results}

The kappa statistics scores for the different assessment criteria ranged from 0.78 to 1.00 for the different evaluations. The mean Cohen kappa for the ART, USPHS and Rye criteria (examiner 1 vs. 2) were $0.92,0.87$ and 0.89 , respectively, indicating good inter-examiner agreement.

Overall, RMGI was better than GIC in each rating system, and no recurrent caries was observed in all fillings. According to the ART criteria, $100 \%$ of RMGI and $92.4 \%$ of GIC restorations were classified as successful after 6 months. The difference between the two materials was statistically significant $\left(\chi^{2}=9.42, p=0.009\right)$. While there was no statistical significance between the results of RMGI at baseline and 6 months, a highly significant difference was observed for GIC fillings $(p=0.0001)$. Generally there was no statistical significance between the baseline-6th month results of each materials and/or cavities (one or two surfaces), except the two surface groups of GIC fillings $\left(\chi^{2}=13.93, p=0.016\right)$.

Based on the modified Ryge criteria with regard to marginal discoloration scores $(84.7 \%=$ Alpha, $15.3 \%=$ Bravo), RMGI was found to be inferior to GIC after 6 months $(p=0.016)$. Regarding wear and marginal adaptation scores, statistically significant differences were found for both RMGI $(p=0.016)$ and GIC $(p=0.05)$ materials, when baseline values were compared at 6 months. However, no difference was observed between the two groups for the wear and marginal adaptation criteria scores after 6 months $\left(\chi^{2}=32.66, p<0.05\right)$. When compared with the GIC material showing 10 Charlie $(26.6 \%)$ and 2 Delta $(5.1 \%)$ scores, the difference between the study materials was statistically significant $(\mathrm{p}=0.0001$, $\chi^{2}=35.7$; table 1 ).

According to the USPHS criteria, the failure rates obtained were close, even similar to those obtained using the modified Ryge criteria. There was a statistically sig- 
Table 1. Results according to the USPHS, ART and modified Ryge criteria

\begin{tabular}{|c|c|c|c|c|}
\hline & RMGI & GIC & $\chi^{2}$ & $\mathrm{p}$ \\
\hline \multicolumn{5}{|c|}{$U S P H S^{\mathrm{a}}$} \\
\hline \multicolumn{5}{|c|}{ Anatomic form } \\
\hline A & $45(86.5)$ & $21(53.8)$ & & \\
\hline $\mathrm{B}$ & $7(13.5)$ & $14(35.9)$ & & \\
\hline $\mathrm{C}$ & & $4(10.3)$ & $13.47^{\mathrm{b}}$ & 0.001 \\
\hline \multicolumn{5}{|c|}{ Retention } \\
\hline 0 & $52(100)$ & $38(97.4)$ & & \\
\hline 1 & & $1(2.6)$ & 1.34 & 0.24 \\
\hline \multicolumn{5}{|c|}{ Marginal discoloration } \\
\hline 0 & $43(82.7)$ & $35(89.7)$ & & \\
\hline 1 & $9(17.3)$ & $4(10.3)$ & 0.90 & 0.34 \\
\hline \multicolumn{5}{|c|}{ Marginal adaptation } \\
\hline 0 & $43(82.7)$ & $32(82.1)$ & & \\
\hline 1 & $9(17.3)$ & $5(12.8)$ & & \\
\hline 2 & & $2(5.1)$ & 2.95 & 0.27 \\
\hline \multicolumn{5}{|c|}{ ART score } \\
\hline 0 & $48(92.3)$ & $23(59)$ & & \\
\hline 1 & $4(7.7)$ & $12(30.8)$ & & \\
\hline 2 & & $1(2.6)$ & & \\
\hline 3 & & $1(2.6)$ & & \\
\hline 4 & & $1(2.6)$ & & \\
\hline 7 & & $1(2.6)$ & $15.25^{\mathrm{b}}$ & 0.009 \\
\hline \multicolumn{5}{|c|}{ Modified Ryge } \\
\hline \multicolumn{5}{|c|}{ Marginal discoloration } \\
\hline 0 & $43(82.7)$ & $33(84.6)$ & & \\
\hline 1 & $8(15.4)$ & $5(12.8)$ & & \\
\hline 2 & $1(1.9)$ & $1(2.6)$ & 0.15 & 0.92 \\
\hline \multicolumn{5}{|c|}{ Wear } \\
\hline 0 & $44(84.6)$ & $32(82.1)$ & & \\
\hline 1 & $7(13.5)$ & $5(12.8)$ & & \\
\hline 2 & $1(1.9)$ & $2(5.1)$ & 0.71 & 0.69 \\
\hline \multicolumn{5}{|c|}{ Marginal adaptation } \\
\hline 0 & $42(80.8)$ & $31(79.5)$ & & \\
\hline 1 & $9(17.3)$ & $4(10.3)$ & & \\
\hline 2 & $1(1.9)$ & $2(5.1)$ & & \\
\hline 3 & & $2(5.1)$ & 4.14 & 0.24 \\
\hline \multicolumn{5}{|c|}{ Surface texture } \\
\hline 0 & $45(86.5)$ & $10(25.6)$ & & \\
\hline 1 & $6(11.5)$ & $17(43.6)$ & & \\
\hline 2 & $1(1.9)$ & $10(25.6)$ & & \\
\hline 3 & & $2(5.1)$ & $35.77^{\mathrm{b}}$ & 0.0001 \\
\hline
\end{tabular}

Figures in parentheses indicate percentages.

${ }^{a}$ Caries score was not included.

${ }^{\mathrm{b}}$ Statistically significant.

nificant difference in marginal discoloration of RMGI $(p=0.008)$, but not GIC. Anatomic form was unsatisfactory in $10.3 \%$ (4 fillings as Charlie) of GIC fillings. By contrast, no filling was found unsatisfactory in the RMGI group.

\section{Discussion}

The evidence supporting minimal restorative interventions resembling ART cavities shows that minute cavities can be successfully treated while preserving tooth structure and without increasing the risk of restoration failure [3]. In our study, the success rates of GIC fillings were considerably higher than that reported by Pitiphat et al. [4] in Thailand, but similar to that of Phantumvanit et al. [2] and Ho et al. [5]. Our 6-month results obtained from the modified Ryge and USPHS rating systems seem considerably similar to that of Dutta et al. [6], although the study was performed in primary dention.

Although not common, a few ART studies have recently used the USPHS criteria to evaluate ART fillings and/or sealants. In one of these, the failure rates obtained were close to, but lower than those obtained using the ART criteria [7, 8]. In their study, Lo et al. [7] clearly confirmed that after 24 months, there was no statistically significance between the two GIC materials (ChemFlex and Fuji IX GP) placed on permanent dentitions using the ART technique. With respect to the USPHS criteria, the results of this study are close to those of our GIC group, but lower than those of the RMGI group, except in the marginal discoloration category.

Even though the duration of this study is too short to compare with any other ART studies using split mouth techniques, performing RMGI fillings seem logical.

\section{Conclusion}

Generally, for each rating system, RMGI exhibited better clinical performance than GIC in all categories, except for marginal discoloration. Based on the 6-month evaluation, our results show that RMGI can be an alternative material to GIC. 


\section{References}

1 Mickenautsch S, Rudolph MA, Ogunbodede EO, Frencken JE: The impact of the ART approach on the treatment profile in a mobile dental system (MDS) in South Africa. Int Dent J 1999;49:132-138.

$\checkmark 2$ Phantumvanit P, Songpaisan Y, Pilot T, Frencken JE: Atraumatic restorative treatment (ART): A three-year community field trial in Thailand - Survival of one-surface restorations in the permanent dentition. J Public Health Dent 1996;56:141-145.

$>3$ Tyas MJ, Anusavice KJ, Frencken JE, Mount GJ: Minimal intervention dentistry - a review. FDI commission project. Int Dent J 2000;50: $1-12$.
4 Pitiphat W, Bhudhasti V, Phantumvanit P, Frencken J: Atraumatic treatment of dental caries in rural Thailand: 6-month evaluation. J Dent Res 1993;72:838-841.

5 Ho TFT, Smales RJ, Fang DTS: A 2-year clinical study of two glass ionomer cements used in the atraumatic retorative treatment (ART) technique. Com Dent Oral Epidemiol 1999; 27:195-201.
6 Dutta BN, Gauba K, Tewari A, Chawla HS: Silver amalgam versus resin modified GIC class-II restorations in primary molars: Twelve month clinical evaluation. J Indian Soc Pedod Prev Dent 2001;19:118-122.

7 Lo ECM, Luo Y, Fan MW, Wei SHY: Clinical investigation of two glass-ionomer restoratives used with the atraumatic restorative treatment approach in China: Two-year results. Car Res 2001;35:458-463.

$\checkmark 8$ Mandari GJ, Truin GJ, van't Hof MA, Frencken JE: Effectiveness of three minimal intervention approaches for managing dental caries: Survival of restorations after 2 years. Caries Res 2001;35:90-94. 